\title{
Implementation of MCDM-Based Integrated Approach to Identifying the Uncertainty Factors on the Constructional Project
}

\author{
Raana Bagheri ${ }^{10},{ }^{1}$ Zahra Borouji, ${ }^{2}$ Seyed Behnam Razavian, ${ }^{3}$ \\ Mohammad Mahdi Keshvari, ${ }^{3}$ Farzad Sharifi, ${ }^{4}$ and Sara Sharifi ${ }^{5}$ \\ ${ }^{1}$ Department of Management, Science \& Technology, Amirkabir University of Technology (Tehran Polytechnic), Tehran, Iran \\ ${ }^{2}$ Department of Architecture, Faculty of Architecture, Dr. Shariaty Technical and Vocational University, Tehran, Iran \\ ${ }^{3}$ Department of Industrial Management, Binaloud Institute of Higher Education, Mashhad, Iran \\ ${ }^{4}$ Department of Industrial Engineering, Yazd University, Yazd, Iran \\ ${ }^{5}$ Department of Industrial Management, Yazd University, Yazd, Iran
}

Correspondence should be addressed to Raana Bagheri; raana_bagheri@aut.ac.ir

Received 7 July 2021; Revised 30 July 2021; Accepted 13 August 2021; Published 3 September 2021

Academic Editor: Mohammad Yazdi

Copyright (c) 2021 Raana Bagheri et al. This is an open access article distributed under the Creative Commons Attribution License, which permits unrestricted use, distribution, and reproduction in any medium, provided the original work is properly cited.

\begin{abstract}
Presently, environmental management for companies emphasizing environmental protection has become one of the most critical issues for customers, shareholders, governments, employees, competitors, and global pressures requiring organizations to produce environmentally-friendly products and services. This challenge has created a new concept called green supply chain management in business, which combines environmental thinking with the supply chain. Selection of suppliers by considering risk criteria is a category that has attracted the attention of a large number of researchers in order to select the best suppliers according to uncertain factors. In this research, we aim to select a green supplier considering risk factors using a new MCDM approach under uncertainty. For this selection problem, HF-MAIRCA, a new multicriteria sorting method for many alternatives, has been developed. This is used for sorting the alternatives into predefined, ordered supplier categories. This sorting method can be applied to different environmental problems that have a large number of alternatives. As a result of Iran's case study, the result shows that materials flexibility and materials quality are essential criteria for green supplier selection.
\end{abstract}

\section{Introduction}

Supply chain management is a serious and fundamental matter to take into account [1-4]. Companies use SCM to effectively provide reliable, flexible, and cheaper products to maintain their competitiveness [5-8]. The process of selecting the right supplier that can meet the customer's needs in terms of quality, price, and punctuality is one of the essential elements in creating a supply chain [9-12]. The selection of the right supplier is critical to a company's manufacturing and distribution operations [13-16]. An abundance of seasoned companies asserts that supplier recruitment is crucial for a business [17-20]. Choosing the wrong suppliers will result in significant financial losses for the business [21-24]. Reducing production costs is a critical skill in today's hypercompetitive market. By identifying suppliers who will meet the organization's needs, a significant reduction in production costs can be realized, and the company's competitiveness will be enhanced [25-28]. A large portion of the final product cost is included in raw materials and components in almost all industries $[15,29-31]$.

Increasing environmental concerns attract the attention of governments [32-35], customers, and organizations [36-46]. These worries made them define some environmental perquisites in their line of products; since most of the materials and components of products come from external suppliers, having a keen eye on environmental criteria in the supply chain process seems necessary [8, 47-49]. Due to the increasing environmental hazards caused by industrial activities, paying more attention to this issue and making sustainable processes are vital. Green supply chain 
management considers the effects of human toxicology and integrates environmental concerns into supply chain management [50-53]. No company today can give up supply chain management and expect its survival [54-57].

Assessment and selection of a decent supplier are among the main tasks in making a sustainable supply chain, which is a significant concern for conserving the environment [58-61].

Construction industry is one of today's essential industries to consider [62-65]. Since Iran's construction companies depend on a stable supply chain, implementing a green supply chain is essential $[8,66-68]$. It is possible to implement green supply chain management in the construction industry to manage their natural resource consumption $[4,36,69,70]$. Additionally, it can help the construction process as a whole be more efficient. Green supply chain management in the construction industry has previously been shown to benefit the business. This product may benefit the organization in several ways, including reducing production costs, protecting the environment, and making a significant contribution to sustainable development. Recruiting a green contractor is a crucial part of supply chain management. It has long-term environmental impacts [71-74].

Choosing a green supplier is a multicriteria decisionmaking problem $[48,75,76]$. The primary purpose of this study is to identify and prioritize the items for choosing green suppliers in the construction industry and then to rank suppliers based on the items identified using a new approach $[25,77-79]$.

Many MCDM methods have been introduced for supplier selection. One method to be named is the VIKORSORT [80] method which evaluates the green supplier based on the formula of multicriteria sorting method.

The suppliers got candidates based on AHP Sort II with the type 2 fuzzy distance method in a robust supplier selection problem [81, 82]. Unfortunately, the construction project risk in the supplier selection process has not been considered in previous articles. SC operations are exposed to a variety of risks as a result of globalization. Risky constraints surround the supply chain projects. These emerging constraints should be looked at like a strategic issue that needs to be addressed by SC managers.

Analysis of the green supplier performance and its impact on uncertain variables is essential in choosing effective suppliers. Having said this, it is necessary to have a risk-based supplier selection and sorting method.

It can be stated that there is no feasible approach on integrated multicriteria decision-making methods for sorting green suppliers based on the uncertainty in the construction projects. In order to fill this gap, this study proposes a new multicriteria method based on MAIRCA. This article is based on two principles: first, a MAIRCAbased method called hesitant fuzzy MAIRCA and, second, using the proposed method to rank green suppliers based on the uncertainty of their construction projects.

In this research, we seek to develop a new integrated model of entropy-MAIRCA based on hesitant fuzzy set to select a green supplier in the construction industry under uncertainty.

\section{Literature Review}

2.1. Green Supply Chain. A world with rising greenhouse gas emissions and rising global temperatures is confronted with various global issues such as global warming, pollution, and various other environmental threats [83]. The discovery of these problems could result in the extinction of the human race. Due to this, environmental preservation programs quickly became essential priorities in business due to their ability to lead to organizational innovation $[84,85]$. One hand focused on profitability and the other hand on minimizing or eliminating waste. This location played a vital role in the development of the green supply chain. The Michigan State University Industrial Research Association launched green supply chain management in 1996. It is a new environmental protection management model $[85,86]$. All stages of raw materials, product design and manufacturing, product sales and transportation, product use, and product recycling are all involved in the "green supply chain management" strategy from a product life cycle perspective. Reducing the negative environmental impacts while utilizing optimal resources and energy is possible by implementing supply chain management and green technology $[87,88]$.

The greening of the supply chain is the process throughout the supply chain to consider environmental criteria or considerations. Supply chain management that is green uses all aspects of design, supply chain selection, and green, from conception to completion, as tools for integrating supply chain management with environmental requirements [89, 90].

The concept of sustainable or green supply chain integration encompasses environmentally sustainable practices employed in the traditional supply chain [88]. This may include selecting suppliers and purchasing material, the design of products, the production of products, and the management of final distribution and disposal [85]. Rather than attempting to soften the impact of business and supply chain operations, the green supply chain involves providing value in the form of product or service improvement, plus/or product or service creation, via the operations of the entire supply chain $[87,91-93]$. The main goal of the green supply chain is to reduce pollution in the air, water, and waste $[37,38,70,94]$. However, while attempting to meet this goal, companies can also reduce waste manufacturing, reuse, and recycling, manufacturing costs, asset efficiency, image building, and customer satisfaction [39-41, 95]. The benefits of green supply chain areas are shown in Figure 1.

2.2. Green Supplier Selection. The increase of production level from corporations is an unintended consequence of industrial booming and has continued up until today [96]. The adverse effects of later events have led the production processes to adopt new strategies in the environmental management field to maintain their position. One solution is to conflate the greenness issues in supply chains, which will significantly affect the performance of suppliers $[83,85,86,88]$. Therefore, evaluating and selecting a green supplier are a strategic decision to maintain a competitive market and social position for companies [50,97]. 


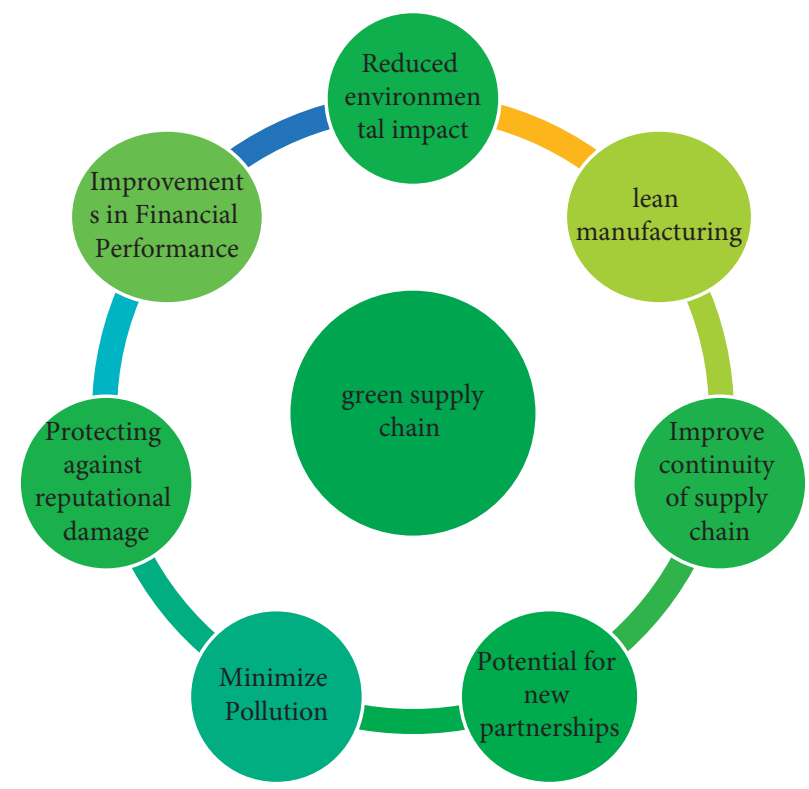

Figure 1: The benefits of green supply chain.

There is much literature evaluating and selecting green suppliers, but there is relatively limited research on evaluating and selecting a green supplier at risk. Recently, research on the evaluation and selection of green suppliers has attracted many academic and industrial sectors [93].

Researchers have developed various tools and techniques for supplier selection, most of which are multicriteria decisionmaking techniques. An integrated green supplier selection approach is introduced with the ANP process and improved gray relationship analysis $[4,14,42-46,48,49,63-65,98-101]$. A case study of the food industry to select a green supplier using fuzzy group multicriteria decision-making methods has undergone investigation [16]. Green supplier selection was made using the AHP-entropy-TOPSIS framework [102]. Using the TODIM multicriteria group decision method, a green supplier was selected in the type 2 interval fuzzy environment [103]. In [29], the green supplier selection modeling is done to integrate the DANP model with the VIKOR model.

Artificial intelligence can be a valuable tool for supplier selection. An "intelligent agent" is a system that, by knowing its surroundings, increases its chances of success after analysis $[37,38]$. Artificial intelligence in the industry today: due to the spread of knowledge and more complex decisionmaking process, the use of information systems, especially artificial intelligence systems in decision making, has become more important [39-42]. The spread of knowledge in the field of technology and industry and the complexity of environmental decisions-in other words, human life-has attracted the attention of experts for the use of decision support systems in environmental affairs [43, 44].

Also, in some green supplier articles, multicriteria decision-making and other methods were performed. For example, in [13], artificial neural networks and MADA methods were used in a combined model to select the green supplier. An integrated QFD-MCDM framework was demonstrated for green supplier selection [14]. Selection and evaluation of green suppliers were made using the DEA method [67]. Selection and evaluation of green suppliers were made by combining ANP and IPA methods to achieve sustainable management for the green supply chain [62]. Evaluation and selection of green suppliers were made using cloud model theory and QUALIFLEX method [104].

\subsection{Green Supply Chain in the Construction Industry.} Many conductive kinds of research have undergone investigation on supplier selection in construction projects. In improving the quality of life in urban environments, the building sector has a significant impact. The greening of the supply chain is a significant challenge and needs to be addressed adequately in the building industry. Paper [26] seeks to select green suppliers for building projects in public universities in Iran through the rough theory of multicriteria decision models. In [27], a new approach is demonstrated for the dynamic decision-making multicriterion choice of green suppliers for construction projects in the time sequences presented. Sustainable development is one of the most undeniable preconditions for resource conservation and balances the performance of a complete supply chain in various regions. Given the complexity of sustainable development and supply chain, different decisions have to be made daily, which requires various substantial parameters to be considered. In [24], a new hybrid MCDM model, which includes COPRAS, ARAS, WASPAS, SAW, and MABAC, is developed to evaluate and select suppliers in a supply chain for construction companies.

During the last decade, supply chain management for construction managers has become a new challenge to obtain the appropriate material and budget on time. In [105], the choice evaluation for the supplier was carried out by the ANP method for building materials such as cladding and roof constructions. 
Choosing a supplier as a strategic decision plays a significant role in issues that have attracted the attention of researchers $[4,63]$. Suppliers are the first part of the chain, and any failure in this tire will continue in the chain, and its effect will be intensified until the end. It is impossible to produce high-quality, low-cost products or services without having proper decent suppliers in today's competitive world $[24,105]$. From the decision-making point of view, different and conflicting criteria must be taken account of, making supplier selection much more ambiguous. In today's open world economy, it is essential to both develop the product and expand supplier lines simultaneously; evaluating and selecting suppliers are a must $[75,96]$.

Reducing production costs is a crucial law of survival in today's highly competitive environment [106]. The selection of appropriate providers can considerably reduce costs and enhance the organization's competitiveness; that is why in most industries the cost of raw materials and product components engages a large portion of the company's liquidity for the product to take over the market [89]. Increasing concerns about environmental warnings have attracted the attention of governments, customers, and organizations. They discovered the importance of meeting environmental requirements in their productions since most of the materials and components come from external suppliers [90]. Hence, it is crucial to pay attention to environmental criteria in the procurement process. Making a supply chain green is an opportunity for those concerned about sustainable consumption issues and environmental practices $[90,107]$. Since most of the materials and components of products are supplied from external suppliers, it is essential to pay attention to environmental criteria in the procurement process. Making a supply chain green is an opportunity for those concerned about sustainable consumption issues and environmental business practices [95, 108-110].

\section{Research Methodology}

3.1. Hesitant Fuzzy Set. The inherent complexity of natural objects and human inability to fully comprehend such things pose significant problems when it comes to making decisions that rely on information $[64,111]$. Most of the issues and challenges faced by decision makers and planners are multiobjective, which adds to the analytical difficulties [4, 65]. Many of the simplifications of the past-for example, that in a given decision only the minimum or maximum cost or benefit is essential-are not acceptable today, and it is necessary to confront the actual situation as much as possible with the methods and utilize more progressive approaches $[98,99]$. These methods take a more comprehensive look at issues such as the multiplicity of futures, the multiplicity of goals, the changing attitudes towards risk, and, most importantly, the inevitable balances [100, 101]. Fuzzy sets (FS) were developed by the mathematician Lotfi Zadeh [95] to deal with real-life decisions that are complicated due to the inherent uncertainty. Decision making was aided by fuzzy sets, which Zadeh pioneered in 1965. Afterward, as the progression of decision-making science has progressed, various fuzzy sets have been developed [93]. Torra first proposed the hesitant fuzzy sets concept in 2011.
In contrast to classic fuzzy sets, which have more significant disadvantages, hesitant fuzzy sets have more significant advantages [83]. While applying the classical methods, we have discovered a subtle error that led to a problem with membership values. Thus, we have become motivated to look into hesitation fuzzy sets because this issue has been solved by defining a list of possible values. This issue has been dealt with. By establishing a membership degree as a measurement of the hesitant fuzzy decisionmaking methods, interval-assignment is less accurate than membership, indicating that hesitant fuzzy methods of decision making are more accurate than other methods [112].

Definition 1 (see [69]). A fuzzy set with an affiliation function $m F$ is in a reference set like $X$ with $[0,1]$ values such as

$$
\mu_{F}: X \longrightarrow[0,1]
$$

Atanassov defined the concept of Intuitive Fuzzy Set (IFS) after introducing the function of fuzzy sets in the decision-making process to express decision-makers preferences more precisely.

Let $h, h 1$, and $h 2$ be three HFEs; then $[111,112]$,

$$
\begin{aligned}
& \text { (1) } h^{\lambda}=\bigcup_{\gamma \in h}\left\{\gamma^{\lambda}\right\} \text {; } \\
& \text { (2) } \lambda h=\bigcup_{\gamma \in h}\left\{1-(1-\gamma)^{\lambda}\right\} \text {; } \\
& \text { (3) } \tilde{h}_{1} \cup \widetilde{h}_{2}=\underset{\gamma_{1} \in \tilde{h}_{1}, \gamma_{2} \in \widetilde{h}_{2} \operatorname{Max}\left\{\gamma_{1}, \gamma_{2}\right\}}{\bigcup} \text {; } \\
& \text { (4) } \tilde{h}_{1} \cap \tilde{h}_{2}=\underset{\gamma_{1} \in \tilde{h}_{1}, \gamma_{2} \in \widetilde{h}_{2} \operatorname{Min}\left\{\gamma_{1}, \gamma_{2}\right\}}{\bigcup} \text {; } \\
& \text { (5) } h_{1} \oplus h_{2}=\underset{\gamma_{1} \in h_{1}, \gamma_{2} \in h_{2}\left\{\gamma_{1}+\gamma_{2}-\gamma_{1} \gamma_{2}\right\}}{\bigcup^{\prime}} \text {; } \\
& \text { (6) } h_{1} \otimes h_{2}=\bigcup_{\gamma_{1} \in h_{1}, \gamma_{2} \in h_{2}\left\{\gamma_{1} \gamma_{2}\right\}} \text {. }
\end{aligned}
$$

Definition 2 (see [69]). If the reference set $X=\{x 1, x 2, \ldots$, $x n$, the intuitionist fluid set $A$ is defined as the following in the reference set $X$ :

$$
A=\left\{\left\langle x_{i}, \mu\left(x_{i}\right), v\left(x_{i}\right)\right\rangle \mid x_{i} \in X\right\}
$$

Moreover, in the following conditions for all values are membership function and nonmembership function in the $[0,1]$ interval:

$$
0 \leq \mu\left(x_{i}\right)+\nu\left(x_{i}\right) \leq 1 .
$$

For set $A$, we have $\pi_{A}\left(x_{i}\right)$, which is the uncertainty $x_{i}$ value:

$$
\pi_{A}\left(x_{i}\right)=1-\mu\left(x_{i}\right)-v\left(x_{i}\right) .
$$


Definition 3 (see [69]). A hesitant fluid element, such as $H$ in $A$, is an HFS function defined as a $h$ subset when an interviewing reference setting $[0,1]$ is applied. The hesitant fluid set is the generalization of intuitionist fluids. $\mathrm{Xu}$ and Xia define this set as follows to make it comfortable:

$$
H=\left\{\left\langle x_{i}, h\left(x_{i}\right)\right\rangle \mid x_{i} \in X\right\}
$$

where $h\left(x_{i}\right)$ is a set of various interval values $[0,1] . h\left(x_{i}\right)$ is referred to as the hesitant HFE element.

Definition 4 (see [93]). If the $X$ reference set is $h(x)=\{\mu 1, \alpha 2, \ldots, \mu 1\}$, then the HFE mean of $h(x)$ is defined by the following formula for a set of possible values of $\mu m k(k=1,2, \ldots, 1)$ and 1 is the value for $h(x)$. Consider the following:

$$
\bar{h}(x)=\frac{1}{l} \sum_{k=1}^{l} \gamma_{k}
$$

A definition of value operator and variance operator is required to compare the rules of hesitant fuzzy elements.

Definition 5 (see [69]). The value operator per HFE is the following:

$$
s(h)=\frac{1}{l_{h}} \sum_{\gamma \varepsilon h} \gamma
$$

It is clear that, if $s(h 1)>s(h 2)$ are $h 1>h 2$ and the two values are the same $s(h 1)=s(h 2)$, then $h 1=h 2$.

When two values are compared, it does not matter if one is hesitant or fuzzy because the value operator is the same for both. Moreover, the variance operator is defined as a supplementary concept.

Definition 6 (see [69]). The formula for each HFE is the following:

$$
v_{1}(h)=\frac{1}{l_{h}} \sqrt{\sum_{\gamma_{i}, \gamma_{j} \in h}\left(\gamma_{i}-\gamma_{j}\right)^{2}} .
$$

For both HFE elements such as $h 1$ and $h 2$, if $v 1(h 1)$ $>v 1(h 2)$, then $h 1<h 2$.

\subsection{The Proposed Model (Hesitant Fuzzy Entropy-MAIRCA)}

3.2.1. Uncertainty Entropy Method. The entropy procedure is a method of weighting. The weighting method of uncertainty and hesitant fuzzy is a new method of weighing the criteria in a situation where experts' assessment for different reasons is possible, such as many experts, and the problem needs to be weighed under uncertainty.

The following steps are taken in this way [69]:

Step 1: use the following formula to calculate the hesitant fuzzy score Sij on the Expert Opinions matrix:

$$
s\left(h_{E}(x)\right)=\sum_{j=1}^{l\left(h_{E}(x)\right)} \frac{h_{E}^{\sigma(j)}(x)}{l\left(h_{E}(x)\right)} .
$$

Step 2: the computation of the normalized matrix $S$ is calculated based on the computation in the previous step:

$$
s_{i j}^{\prime}=\frac{s_{i j}}{\sum_{i=1}^{m} s_{i j}} .
$$

Step 3: with the use of De Luca-Termini entropy under hesitant fuzzy sets, we have

$E_{j}=-\frac{1}{m \ln 2} \sum_{i=1}^{m}\left(s_{i j}^{\prime} \ln s_{i j}^{\prime}+\left(1-s_{i y}^{\prime}\right) \ln \left(1-s_{y}^{\prime}\right)\right), \quad j=1,2, \ldots, n$.

Step 4: a formula that describes the weight of the features is

$$
w_{j}=\frac{1-E_{j}}{\sum_{j-1}^{n}\left(1-E_{j}\right)}, \quad j=1,2, \ldots, n .
$$

$W_{J}$ is the subcriteria's weight.

3.2.2. HF-MAIRCA Method. This method is done in six steps [97, 113].

Step 1: form a decision matrix $H$ (see Table 1).

Step 2: determine the distance between two hesitant fuzzy elements through the following formula:

$$
d\left(h_{M}, h_{N}\right)=\frac{1}{l} \sum_{k=1}^{l}\left|h_{M}^{\sigma(k)}-h_{N}^{\sigma(k)}\right| .
$$

Now, the following formulas will be used to calculate the value and variance operators of hesitant fuzzy sets:

$$
s(h)=\frac{1}{l_{h}} \sum_{\gamma \in h} \gamma .
$$

Step 3: determine the hesitant fuzzy priority based on the choice of options $\left(P_{S h}\right)$.

When deciding on the work process, the decision maker is unbiased. He is unenthusiastic about any of the available options. People often make a faulty assumption when they assume that the decision maker ignores the probabilities associated with each option. Since each $m$ option can be visually equivalent, the decision maker must decide based on this equation.

$$
\begin{aligned}
P_{S h_{i}} & =\frac{1}{m}, \\
\sum_{i=1}^{m} P_{s h} & =1, \\
i & =1,2, \ldots, m .
\end{aligned}
$$


TABle 1: Decision matrix.

\begin{tabular}{ccccc}
\hline & $C_{1}$ & $C_{2}$ & $\ldots$ & \\
\hline$A_{1}$ & $H_{11}$ & $H_{12}$ & $\ldots$ & $C_{n}$ \\
$A_{2}$ & $H_{21}$ & $H_{22}$ & $\ldots$ & $H_{1 n}$ \\
$\ldots$ & $\ldots$ & $\ldots$ & $\ldots$ & $\ldots$ \\
$A_{m}$ & $H_{m 1}$ & $H_{m 2}$ & $\ldots$ & $\ldots$ \\
\hline
\end{tabular}

$M$ specifies the total number of options in the above relation. In the context of decision analysis, we assume that the decision maker is risk-neutral concerning the probabilities listed. When it comes to this particular option, all preferences are equivalent; i.e., all $P_{S h}$ are equal.
Step 3: calculate the theoretical evaluation matrix elements $\left(T_{p}\right)$.

Theoretical evaluation matrix $\left(T_{p}\right)$, in the format $n * m$, is the total criteria number, and $m$ is the total option number. As a coefficient of preference as $P_{S h}$ options and as a weight, the elements of the theoretical evaluation matrix (tpij) are calculated as follows:

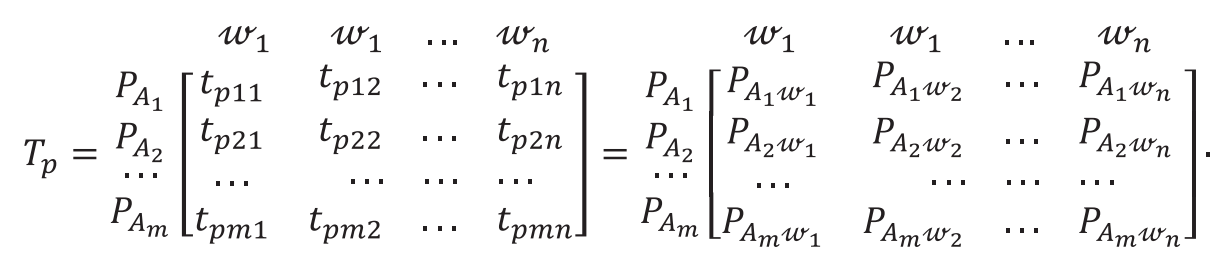

Since the decision maker for the initial selection of options is neutral, all preferences $\left(P_{A i}\right)$ are equal. Then, the above equation can be shown in the following equation:

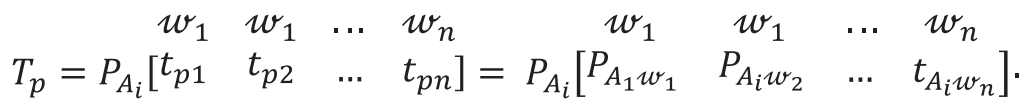

Step 4: determine the accurate evaluation equation.

The computation of the elements of the actual assessment matrix (Tr) is carried out by multiplying the theoretical evaluation matrix (TP) elements by the following equations and the elements of the initial deciding matrix $(X)$. The first equation is positive, and the second equation is negative.

$$
\begin{aligned}
& t_{r i j}=t_{p i j}\left(\frac{x_{i j}-x_{i}^{-}}{x_{i}^{+}-x_{i}^{-}}\right), \\
& t_{r i j}=t_{p i j}\left(\frac{x_{i j}-x_{i}^{+}}{x_{i}^{-}-x_{i}^{+}}\right) .
\end{aligned}
$$

\section{Step 5: calculate the total gap matrix $(G)$.}

The $G$ matrix elements are calculated as the difference (distance) between theoretical $\left(t_{p i j}\right)$ and real $\left(t_{r i j}\right)$ estimates which are expressed in the following equation. If $g_{i j}$ tends to be zero, a theoretical $\left(t_{p i j}\right)$ and real evaluation $\left(t_{r i j}\right)$ option with the most negligible difference is chosen. In other words, if the theoretical assessment is equal to the actual assessment in the $\mathrm{Ci}$ criterion, compared to the $\mathrm{Ci}$ criterion, the $A i$ option is the best.

$$
G=T_{p}-T_{r}=\left[\begin{array}{cccc}
g_{11} & g_{12} & \cdots & g_{1 n} \\
g_{21} & g_{22} & \cdots & g_{2 n} \\
\cdots & \cdots & \cdots & \cdots \\
g_{m 1} & g_{m 2} & \cdots & g_{m n}
\end{array}\right]=\left[\begin{array}{cccc}
t_{p 11}-t_{r 11} & t_{p 12}-t_{r 12} & \cdots & t_{p 1 n}-t_{r 1 n} \\
t_{p 21}-t_{r 21} & t_{p 22}-t_{r 22} & \cdots & t_{p 2 n}-t_{r 2 n} \\
\cdots & \cdots & \cdots & \cdots \\
t_{p m 1}-t_{r m 1} & t_{p m 2}-t_{r m 2} & \cdots & t_{p m n}-t_{r m n}
\end{array}\right] .
$$


TAвLE 2: Criteria for green supplier selection in construction projects.

\begin{tabular}{lcc}
\hline Criteria & Main criteria & Subcriteria \\
\hline & C1: building materials information & C11: materials \\
C12: materials flexibility \\
C13: materials quality \\
Green supplier selection in construction projects & C2: green business operation & C21: emergency response capability \\
& C22: green logistics & C23: financial capability \\
& C3: potential for sustainable cooperation & C31: the desire for green cooperation \\
& C41: green certifications & C42: ecodesign of materials \\
& C4: green technology capability & C43: green production \\
\hline
\end{tabular}

TABLe 3: $S$ values.

\begin{tabular}{|c|c|c|c|c|c|c|c|c|c|c|}
\hline $\mathrm{C} 11$ & $\mathrm{C} 12$ & $\mathrm{C} 13$ & $\mathrm{C} 21$ & $\mathrm{C} 22$ & $\mathrm{C} 23$ & C31 & $\mathrm{C} 41$ & $\mathrm{C} 42$ & $\mathrm{C} 43$ & \\
\hline $0 / 51$ & $0 / 52$ & $0 / 48$ & $0 / 22$ & $0 / 23$ & $0 / 34$ & $0 / 94$ & $0 / 5$ & $0 / 23$ & $0 / 38$ & \multirow{4}{*}{$s i j$} \\
\hline $0 / 49$ & $0 / 95$ & $0 / 69$ & $0 / 32$ & $0 / 58$ & $0 / 48$ & $0 / 98$ & $0 / 41$ & $0 / 37$ & $0 / 5$ & \\
\hline $0 / 94$ & $0 / 13$ & $0 / 86$ & $0 / 45$ & $0 / 64$ & $0 / 27$ & $0 / 81$ & $0 / 4$ & $0 / 76$ & $0 / 12$ & \\
\hline $0 / 26$ & $0 / 63$ & $0 / 43$ & $0 / 67$ & $0 / 83$ & $0 / 6$ & $0 / 45$ & $0 / 22$ & $0 / 53$ & $0 / 42$ & \\
\hline $2 / 200$ & $2 / 230$ & $2 / 460$ & $1 / 660$ & $2 / 280$ & $1 / 690$ & $3 / 180$ & $1 / 530$ & $1 / 890$ & $1 / 420$ & Sum Sij \\
\hline
\end{tabular}

TABle 4: $S^{\prime}$ values.

\begin{tabular}{|c|c|c|c|c|c|c|c|c|c|}
\hline C11 & $\mathrm{C} 12$ & $\mathrm{C} 13$ & $\mathrm{C} 21$ & $\mathrm{C} 22$ & $\mathrm{C} 23$ & C31 & $\mathrm{C} 41$ & $\mathrm{C} 42$ & $\mathrm{C} 43$ \\
\hline $0 / 1$ & 6666 & 528 & 78 & 075 & 58120 & 27603 & 252525 & 069697 & 81 \\
\hline$-0 / 1$ & $0 / 3044$ & $0 / 219$ & & (2) & & & $0 / 20$ & $0 / 11$ & $0 / 1$ \\
\hline $0 / 28$ & $0 / 0416$ & $0 / 2738$ & $0 / 15$ & $0 / 21$ & $0 / 125$ & $0 /$ & $0 / 20$ & $0 / 23$ & 0/03871 \\
\hline $0 / 078313$ & 0/201923077 & $0 / 13694268$ & $0 / 237589$ & $0 / 273026$ & $0 / 279069767$ & $0 / 108959$ & $0 / 111111$ & $0 / 160606$ & $0 / 135484$ \\
\hline
\end{tabular}

Table 5: Weight of criteria.

\begin{tabular}{|c|c|c|c|c|c|c|c|c|c|c|}
\hline C11 & $\mathrm{C} 12$ & $\mathrm{C} 13$ & $\mathrm{C} 21$ & $\mathrm{C} 22$ & $\mathrm{C} 23$ & C31 & C41 & $\mathrm{C} 42$ & $\mathrm{C} 43$ & \\
\hline$-0 / 42893$ & $-0 / 45056121$ & $-0 / 4276488$ & $-0 / 27389$ & $-0 / 26803$ & $-0 / 43657189$ & $-0 / 53636$ & $-0 / 56509$ & $-0 / 25285$ & $-0 / 37204$ & $s^{\prime} \ln s^{\prime}+1-s^{\prime} \ln 1-s^{\prime}$ \\
\hline$-0 / 41851$ & $-0 / 61461847$ & $-0 / 5265853$ & $-0 / 35372$ & $-0 / 48737$ & $-0 / 53099796$ & $-0 / 54793$ & $-0 / 51005$ & $-0 / 35093$ & $-0 / 4418$ & \\
\hline$-0 / 59589$ & $-0 / 17320521$ & $-0 / 5870851$ & $-0 / 43896$ & $-0 / 51465$ & $-0 / 37789996$ & $-0 / 49498$ & $-0 / 50319$ & $-0 / 53964$ & $-0 / 16382$ & \\
\hline$-0 / 27463$ & $-0 / 50305684$ & $-0 / 3993745$ & $-0 / 54828$ & $-0 / 58625$ & $-0 / 5920726$ & $-0 / 34433$ & $-0 / 34883$ & $-0 / 44067$ & $-0 / 39668$ & \\
\hline$-2 / 59347$ & $-2 / 54030114$ & $-2 / 6213229$ & $-2 / 62005$ & $-2 / 55419$ & $-2 / 57746201$ & $-2 / 62967$ & $-2 / 62754$ & $-2 / 60469$ & $-2 / 54146$ & Sum \\
\hline $0 / 597664$ & $0 / 585410298$ & $0 / 60408169$ & $0 / 603788$ & $0 / 58861$ & $0 / 593973989$ & $0 / 606004$ & $0 / 605514$ & $0 / 600248$ & $0 / 585678$ & $E j$ \\
\hline $0 / 402336$ & $0 / 414589702$ & 0/39591831 & $0 / 396212$ & $0 / 41139$ & $0 / 406026011$ & $0 / 393996$ & $0 / 394486$ & $0 / 399752$ & $0 / 414322$ & $1-E j$ \\
\hline 0/099859 & $0 / 102900646$ & $0 / 09826643$ & $0 / 098339$ & $0 / 102107$ & 0/100775148 & 0/097789 & 0/097911 & 0/099218 & $0 / 102834$ & $w j$ \\
\hline
\end{tabular}

TABle 6: Cumulative decision matrix.

\begin{tabular}{lcccccccccccc}
\hline$w$ & $0 / 099859$ & $0 / 102900$ & $0 / 09826$ & $0 / 098339$ & $0 / 102107$ & $0 / 100775$ & $0 / 097789$ & $0 / 097911$ & $0 / 099218$ & $0 / 102834$ & $0 / 099859$ \\
\hline Type & + & + & + & + & + & + & + & + & + & + & + \\
& C11 & C12 & C13 & C21 & C22 & C23 & C 31 & C41 & C42 & C43 & C11 \\
GT & $3 / 187$ & $3 / 354$ & $0 / 004$ & $0 / 020$ & $3 / 187$ & $4 / 864$ & $3 / 452$ & $0 / 003$ & $2 / 254$ & $3 / 198$ & $3 / 187$ \\
TR & $0 / 005$ & $3 / 574$ & $2 / 325$ & $3 / 354$ & $3 / 017$ & $3 / 147$ & $4 / 110$ & $3 / 574$ & $2 / 325$ & $3 / 147$ & $0 / 005$ \\
WM & $2 / 325$ & $2 / 254$ & $2 / 325$ & $0 / 020$ & $4 / 149$ & $4 / 864$ & $4 / 187$ & $3 / 157$ & $3 / 354$ & $3 / 547$ & $2 / 325$ \\
BA & $5 / 000$ & $4 / 864$ & $4 / 190$ & $3 / 190$ & $4 / 864$ & $4 / 980$ & $5 / 000$ & $4 / 864$ & $4 / 190$ & $3 / 190$ & $5 / 000$ \\
\hline
\end{tabular}


TABLe 7: $t p$ values.

\begin{tabular}{|c|c|c|c|c|c|c|c|c|c|c|c|}
\hline$t p$ & EX1 & EX2 & EX3 & EX4 & EX5 & EC1 & EC2 & EC3 & S1 & S2 & S3 \\
\hline $\mathrm{GT}$ & 024065 & $0 / 025725$ & 42455 & 245 & 0 & & 024447 & 024478 & & & 5 \\
\hline TR & $02-1$ & & & & & & & & & & \\
\hline WN & 2 & & & & & & & & & & 965 \\
\hline BA & $0 / 024965$ & $0 / 025725$ & $0 / 024565$ & $0 / 024585$ & $0 / 025527$ & $0 / 025194$ & $0 / 024447$ & $0 / 024478$ & $0 / 024805$ & $0 / 025709$ & $0 / 024965$ \\
\hline
\end{tabular}

TABLE 8: Values of $t r$.

\begin{tabular}{lccccccccccc}
\hline$t r$ & EX1 & EX2 & EX3 & EX4 & EX5 & EC1 & EC2 & EC3 & S1 & S2 & S3 \\
\hline GT & $0 / 015904$ & $0 / 010842$ & 0 & $0 / 024585$ & $0 / 023177$ & $0 / 001594$ & 0 & 0 & 0 & $0 / 022431$ & $0 / 015904$ \\
TR & 0 & $0 / 01301$ & $0 / 013621$ & 0 & $0 / 025527$ & $0 / 025194$ & $0 / 010392$ & $0 / 017981$ & $0 / 00091$ & $0 / 025709$ & 0 \\
WM & $0 / 011596$ & 0 & $0 / 013621$ & $0 / 024583$ & $0 / 009882$ & $0 / 001594$ & $0 / 011608$ & $0 / 015881$ & $0 / 014093$ & 0 & $0 / 011596$ \\
BA & $0 / 024965$ & $0 / 025725$ & $0 / 024565$ & $0 / 001209$ & 0 & 0 & $0 / 024447$ & $0 / 024478$ & $0 / 024805$ & $0 / 022945$ & $0 / 024965$ \\
\hline
\end{tabular}

TABle 9: Calculation of the total gap matrix $G$.

\begin{tabular}{lccccccccccc}
\hline$t p-t r$ & C11 & C12 & C13 & C21 & C22 & C23 & C31 & C41 & C42 & C43 & C11 \\
\hline GT & $0 / 009061$ & $0 / 014883$ & $0 / 024565$ & 0 & $0 / 00235$ & $0 / 023599$ & $0 / 024447$ & $0 / 024478$ & $0 / 024805$ & $0 / 003278$ & $0 / 009061$ \\
TR & $0 / 024965$ & $0 / 012715$ & $0 / 010944$ & $0 / 024585$ & 0 & 0 & $0 / 014056$ & $0 / 006496$ & $0 / 023895$ & 0 & $0 / 024965$ \\
WM & $0 / 013368$ & $0 / 025725$ & $0 / 010944$ & $1 / 52 \mathrm{E}-06$ & $0 / 015645$ & $0 / 023599$ & $0 / 01284$ & $0 / 008596$ & $0 / 010711$ & $0 / 025709$ & $0 / 013368$ \\
BA & 0 & 0 & 0 & $0 / 023375$ & $0 / 025527$ & $0 / 025194$ & 0 & 0 & 0 & $0 / 002764$ & 0 \\
\hline
\end{tabular}

TABle 10: Ranking alternatives.

\begin{tabular}{lcc}
\hline Alternatives & $Q$ & \\
\hline GT & $0 / 151465$ & 4 \\
TR & $0 / 117655$ & 2 \\
WM & $0 / 147139$ & 3 \\
BA & $0 / 07686$ & 1 \\
\hline
\end{tabular}

Step 6: calculate the sum of the final values of the total gap $(Q)$.

Based on the following equation, we get the final values for each option which are ranked based on those options. The lower the final values for an option, the higher the ranking.

$$
Q_{i}=\sum_{j=1}^{n} g_{i j}, \quad i=1,2, \ldots, m .
$$

\section{Case Study}

Our case study is Aria Asak Construction Company in Iran. The company is about 40 years old and has four leading suppliers (abbreviation of alternatives name company: A1: GT, A2: TR, A3: WM, and A4: BA). In the construction industry, the contractor determines the suppliers of goods and services they use for the project, and the clients then select the contractor. Construction, a project-based business, presents significant environmental risks, and green supply chain management (GSCM) is critical in construction. To successfully implement a project, suppliers aligned with the project objective should be selected for the contractor. The following supply chain management practices help protect the environment: buying green, managing green, marketing green, and reverse logistics, known as reverse logistics by GSCM. A green supply chain is a functional networking pattern in the building industry, which covers the major construction areas, such as construction, as core and infrastructure components, capital flow, information flow, and knowledge flow, and is an aid for the entire lifecycle of the construction project. The selection criteria of green suppliers in this section describe how the qualifications of suppliers in green building technologies, social factors in the construction industry, and environmental capabilities meet the standards required to become a green supplier. Our approach to the selection of the green supplier in building projects includes four main criteria (for example, the price of building materials, the recovery of green, and waste) and ten subcriteria (e.g., building materials information, green business operation, potential for sustainable cooperation, and green technology capability). Table 2 presents criteria for green supplier selection in construction projects.

\section{Findings}

In the first step, we first obtain the weight of the subcriteria (see Tables 3-6 ).

First, we calculate $S$ for the decision matrix.

In the next step, we calculate the value of $S^{\prime}$. 
Now we get the values of $E$ and $1-E$ and use them to get the weight of the criteria.

Now that the weight of the subcriteria has been obtained, the options are ranked. Using the method, we have the following.

Now because we have 4 options, the value of $\mathrm{Ph}$ is 0.25 . So by multiplying the matrix values by the cumulative decision in $\mathrm{Ph}$, the values of $t p$ are obtained (Table 7).

Now, considering that all the criteria are positive, the values of $t r$ are obtained (Table 8).

Finally, the total gap matrix is obtained by subtracting the theoretical evaluation matrix and the real evaluation matrix in Table 9.

This value indicates which option is better in each subcriterion. In general, the value of $t p-t r$ in each criterion for each option is zero, so that, under that criterion, that option is better. For example, according to the first column in the system status criterion (C11), the fourth option, BA, is the best option. GT is also the best option in the option of not depending on the criteria C21. WM is not a good option in any of the criteria. Now the result of the overall ranking is as described in Table 10.

\section{Conclusion}

Carbon emissions reduction has been widely agreed upon across the globe. Healthier and more comfortable living conditions are the direct result of constructing green buildings and a reduction in greenhouse gas emissions in the construction industry. Green building materials are essential for constructors because they can be used to build environmentally-friendly structures while at the same time helping to preserve the environment. GSCM has also become an inevitable option for construction companies due to the market and government pressure. One of the most critical aspects of project construction is to employ green vendors. In this research, we seek to develop a new integrated model of entropy-MAIRCA based on hesitant fuzzy set to select a green supplier in the construction industry under uncertainty. For future research, it is suggested to examine the challenges of the green supply chain in developing countries. It is also suggested to extend other methods of multicriteria decision making like KEMIRA into the MCDM-sorting method in the construction project in developed countries.

\section{Data Availability}

There are no available data for this study.

\section{Conflicts of Interest}

The authors declare that they have no conflicts of interest.

\section{References}

[1] B. Wu, C. Jin, A. Monfort, and D. Hua, "Generous charity to preserve green image? exploring linkage between strategic donations and environmental misconduct," Journal of business research, vol. 131, pp. 839-850, 2021.
[2] Y.-Y. Jin, L.-H. Xie, and H.-B. Yang, "Locally upper bounded poset-valued maps and stratifiable spaces," Topology and Its Applications, vol.1, Article ID 107517, 2020, In press.

[3] B. Li, R. Liang, W. Zhou, H. Yin, H. Gao, and K. Cai, "LBS meets blockchain:an efficient method with security preserving trust in SAGIN," IEEE Internet of Things Journal, vol. 1, p. 1, 2021.

[4] H. Yuan, Z. Wang, Y. Shi, and J. Hao, "A dissipative structure theory-based investigation of a construction and demolition waste minimization system in China," Journal of Environmental Planning and Management, vol. 60, pp. 1-27, 2021.

[5] X. Li, Z. Li, T. Jia, P. Yan, D. Wang, and G. Liu, "The sense of community revisited in Hankow, China: combining the impacts of perceptual factors and built environment attributes," Cities, vol. 111, Article ID 103108, 2021.

[6] J. Li, Z. Hu, V. Shi, and Q. Wang, "Manufacturer's encroachment strategy with substitutable green products," International Journal of Production Economics, vol. 235, Article ID 108102, 2021.

[7] Z. Zhang, S. Liu, and B. Niu, "Coordination mechanism of dual-channel closed-loop supply chains considering product quality and return," Journal of Cleaner Production, vol. 248, Article ID 119273, 2020.

[8] S. Sun, M. Zhou, W. Lu, and A. Davarpanah, "Application of symmetry law in numerical modeling of hydraulic fracturing by finite element method," Symmetry, vol. 12, no. 7, p. 1122, 2020.

[9] T. F. Liao, "Hybrid modulation strategy for reactive compensation of PV gridconnected inverter," Intelligent Automation \& Soft Computing, vol. 25, no. 4, pp. 695-704, 2019.

[10] L. Zhao, W. Wang, and W. Zhang, "SEM-based research on influence factors of energy conservation in operation and maintenance of construction project," Intelligent Automation \& Soft Computing, vol. 25, no. 4, pp. 705-713, 2019.

[11] L. Olatomiwa, S. Mekhilef, S. Shamshirband, and D. Petković, "Adaptive neuro-fuzzy approach for solar radiation prediction in Nigeria," Renewable and Sustainable Energy Reviews, vol. 51, pp. 1784-1791, 2015.

[12] A. Mohammadzadeh, O. Castillo, S. S. Band, and A. Mosavi, "A novel fractional-order multiple-model type-3 fuzzy control for nonlinear systems with unmodeled dynamics," International Journal of Fuzzy Systems, pp. 1-19, 2021.

[13] R. J. Kuo, Y. C. Wang, and F. C. Tien, "Integration of artificial neural network and MADA methods for green supplier selection," Journal of Cleaner Production, vol. 18, no. 12, pp. 1161-1170, 2010.

[14] S. H. Hashemi, A. Karimi, and M. Tavana, "An integrated green supplier selection approach with analytic network process and improved grey relational analysis," International Journal of Production Economics, vol. 159, pp. 178-191, 2015.

[15] M. Yazdani, P. Chatterjee, E. K. Zavadskas, and S. H. Zolfani, "Integrated QFD-MCDM framework for green supplier selection," Journal of Cleaner Production, vol. 142, pp. 3728-3740, 2017.

[16] N. Banaeian, H. Mobli, B. Fahimnia, I. E. Nielsen, and M. Omid, "Green supplier selection using fuzzy group decision making methods: a case study from the agri-food industry," Computers \& Operations Research, vol. 89, pp. 337-347, 2018.

[17] R. Habibifar, A. A. Lekvan, and M. Ehsan, "A risk-constrained decision support tool for EV aggregators participating in energy and frequency regulation markets," Electric Power Systems Research, vol. 185, Article ID 106367, 2020. 
[18] R. Naderi, M. S. Nikabadi, A. A. Tabriz, and M. S. Pishvaee, "Supply chain sustainability improvement using exergy analysis," Computers \& Industrial Engineering, vol. 154, Article ID 107142, 2021.

[19] M. S. Nikabadi, H. Shambayati, and N. Ataei, "Selection of resilient supply portfolio under disruption risks in supply chain," International Journal of Industrial and Systems Engineering, vol. 37, no. 4, pp. 432-462, 2021.

[20] J. Wang, Y. Gao, X. Yin, F. Li, and H. J. Kim, "An enhanced PEGASIS algorithm with mobile sink support for wireless sensor networks," Wireless Communications and Mobile Computing, vol. 2018, Article ID 9472075, 9 pages, 2018.

[21] Z. Liao, J. Wang, S. Zhang, J. Cao, and G. Min, "Minimizing movement for target coverage and network connectivity in mobile sensor networks," IEEE Transactions on Parallel and Distributed Systems, vol. 26, no. 7, pp. 1971-1983, 2014.

[22] S. Nosratabadi, A. Mosavi, S. Shamshirband, E. Kazimieras Zavadskas, A. Rakotonirainy, and K. W. Chau, "Sustainable business models: a review," Sustainability, vol. 11, no. 6, p. 1663, 2019.

[23] J. Zhang, X. Jin, J. Sun, J. Wang, and A. K. Sangaiah, "Spatial and semantic convolutional features for robust visual object tracking," Multimedia Tools and Applications, vol. 79, no. 21, pp. 15095-15115, 2020.

[24] B. Matić, S. Jovanović, D. K. Das et al., "A new hybrid MCDM model: sustainable supplier selection in a construction company," Symmetry, vol. 11, no. 3, p. 353, 2019.

[25] I. Inayat, S. S. Salim, S. Marczak, M. Daneva, and S. Shamshirband, "A systematic literature review on agile requirements engineering practices and challenges," Computers in Human Behavior, vol. 51, pp. 915-929, 2015.

[26] P. Shojaei, "Rough MCDM model for green supplier selection in Iran: a case of university construction project," Built Environment Project and Asset Management, vol. 10, no. 3, 2020.

[27] S. Yin, B. Li, H. Dong, and Z. Xing, "A new dynamic multicriteria decision-making approach for green supplier selection in construction projects under time sequence," Mathematical Problems in Engineering, vol. 2017, Article ID 7954784, 13 pages, 2017.

[28] M. Younesi Heravi, A. Yeganeh, and S. B. Razavian, "Using fuzzy approach in determining critical parameters for optimum safety functions in mega projects (case study: Iran's construction industry)," in Frontiers in Nature-Inspired Industrial Optimization, pp. 183-200, Springer, Berlin, Germany, 2022.

[29] T. C. Kuo, C. W. Hsu, and J. Y. Li, "Developing a green supplier selection model by using the DANP with VIKOR," Sustainability, vol. 7, no. 2, pp. 1661-1689, 2015.

[30] M. Rezaei, F. Farahanipad, A. Dillhoff, R. Elmasri, and V. Athitsos, "Weakly-supervised hand part segmentation from depth images," in Proceedings of the 14th PErvasive Technologies Related to Assistive Environments Conference, pp. 218-225, Corfu, Greece, June 2021.

[31] V. Torra, "Hesitant fuzzy sets," International Journal of Intelligent Systems, vol. 25, no. 6, pp. 529-539, 2010.

[32] M. R. Mahmoudi, D. Baleanu, S. N. Qasem, A. Mosavi, and S. S. Band, "Fuzzy clustering to classify several time series models with fractional Brownian motion errors," Alexandria Engineering Journal, vol. 60, no. 1, pp. 1137-1145, 2021.

[33] Z. Liu, A. Mohammadzadeh, H. Turabieh, M. Mafarja, S. S. Band, and A. Mosavi, "A new online learned interval type-3 fuzzy control system for solar energy management systems," IEEE Access, vol. 9, pp. 10498-10508, 2021.
[34] C. Mi, Y. Huang, C. Fu, Z. Zhang, O. Postolache, and A. Authors, "Vision-based measurement: actualities and developing trends in automated container terminals," IEEE Instrumentation and Measurement Magazine, vol. 24, no. 4, pp. 65-76, 2021.

[35] M. Nabavi, V. Nazarpour, A. H. Alibak, A. Bagherzadeh, and S. M. Alizadeh, "Smart tracking of the influence of alumina nanoparticles on the thermal coefficient of nanosuspensions: application of LS-SVM methodology," Applied Nanoscience, vol. 11, pp. 2113-2128, 2021.

[36] M. Shafiei Nikabadi and S. B. Razaviyan, "Identification and ranking of effective indicators on the loyalty of the charities in Iranian charities using fuzzy Delphi and structural interpretative equation," Quarterly Journal of Socio-Cultural Development Studies, vol. 6, no. 3, pp. 59-79, 2018.

[37] S. S. Kalantari and A. A. Taleizadeh, "Mathematical modelling for determining the replenishment policy for deteriorating items in an EPQ model with multiple shipments," International Journal of Systems Science: Operations \& Logistics, vol. 7, no. 2, pp. 164-171, 2020.

[38] A. Chapnevis, I. Güvenç, and E. Bulut, "Traffic shifting based resource optimization in aggregated IoT communication," in Proceedings of the 2020 IEEE 45th Conference on Local Computer Networks (LCN), pp. 233-243, IEEE, Sydney, Australia, November 2020.

[39] M. Masoumnezhad, M. Rajabi, A. Chapnevis et al., "An approach for the global stability of mathematical model of an infectious disease," Symmetry, vol. 12, no. 11, p. 1778, 2020.

[40] S. Arasteh, M. Mahdavi, P. N. Bideh, S. Hosseini, and A. Chapnevis, "Security analysis of two key based watermarking schemes based on QR decomposition," in Proceedings of the Electrical Engineering (ICEE), Iranian Conference on, pp. 1499-1504, IEEE, Mashhad, Iran, May 2018.

[41] A. Chapnevis and B. Sadeghiyan, "A secure two-party computation protocol for intersection detection between two convex hulls," 2020, https://arxiv.org/abs/2011.00319.

[42] H. Safari-Katesari, S. Y. Samadi, and S. Zaroudi, "Modelling count data via copulas," Statistics, vol. 54, no. 6, pp. 1-27, 2020.

[43] H. Safari-Katesari and S. Zaroudi, "Analysing the impact of dependency on conditional survival functions using copulas," Statistics in Transition New Series, vol. 22, no. 1, pp. 217-226, 2021.

[44] H. Safari-Katesari and S. Zaroudi, "Count copula regression model using generalized beta distribution of the second kind," Statistics in Transition New Series, vol. 21, no. 2, pp. 1-12, 2020.

[45] H. S. Katesari and S. Zarodi, "Effects of coverage choice by predictive modeling on frequency of accidents," Caspian Journal of Applied Sciences Research, vol. 5, no. 3, 2016.

[46] H. S. Katesari and B. F. Vajargah, "Testing adverse selection using frank copula approach in Iran insurance markets," The Journal of Mathematics and Computer Science, vol. 15, no. 2, pp. 154-158, 2015.

[47] M. Zhu, L. Yu, X. Zhang, and A. Davarpanah, “Application of implicit pressure-explicit saturation method to predict filtrated mud saturation impact on the hydrocarbon reservoirs formation damage," Mathematics, vol. 8, no. 7, p. 1057, 2020.

[48] Z. Xiong, N. Xiao, F. Xu et al., “An equivalent exchange based data forwarding incentive scheme for socially aware networks," Journal of Signal Processing Systems, vol. 93, no. 2, pp. 249-263, 2021. 
[49] H. Zhao and S. Guo, "Selecting green supplier of thermal power equipment by using a hybrid MCDM method for sustainability," Sustainability, vol. 6, no. 1, pp. 217-235, 2014.

[50] H. Gao, Y. Ju, E. D. S. Gonzalez, and W. Zhang, "Green supplier selection in electronics manufacturing: an approach based on consensus decision making," Journal of Cleaner Production, vol. 245, Article ID 118781, 2020.

[51] T. E. Simos and C. Tsitouras, "Evolutionary derivation of Runge-Kutta pairs for addressing inhomogeneous linear problems," Numerical Algorithms, vol. 87, pp. 511-525, 2020.

[52] H. Zhang and Y. Cui, "A model combining a Bayesian network with a modified genetic algorithm for green supplier selection," Simulation, vol. 95, no. 12, pp. 1165-1183, 2019.

[53] B. H. Li, Y. Liu, A. M. Zhang, W. H. Wang, and S. Wan, "A survey on blocking technology of entity resolution," Journal of Computer Science and Technology, vol. 35, no. 4, pp. 769-793, 2020.

[54] X. Hu, J. Xie, W. Cai, R. Wang, and A. Davarpanah, "Thermodynamic effects of cycling carbon dioxide injectivity in shale reservoirs," Journal of Petroleum Science and Engineering, vol. 195, Article ID 107717, 2020.

[55] W. Li, J. Y. Guo, M. Yazdi, A. Nedjati, and K. A. Adesina, "Supportive emergency decision-making model towards sustainable development with fuzzy expert system," Neural Computing \& Applications, vol. 1, pp. 1-9, 2021.

[56] G. J. Jiang, H. X. Chen, H. H. Sun, M. Yazdi, A. Nedjati, and K. A. Adesina, "An improved multicriteria emergency decision-making method in environmental disasters," Soft Computing, vol. 25, pp. 1-29, 2021.

[57] J. Zhang, M. Wang, Y. Tang et al., "Angular velocity measurement with improved scale factor based on a widebandtunable optoelectronic oscillator," IEEE Transactions on Instrumentation and Measurement, vol. 70, 2021.

[58] A. Davarpanah, B. Mirshekari, T. J. Behbahani, and M. Hemmati, "Integrated production logging tools approach for convenient experimental individual layer permeability measurements in a multi-layered fractured reservoir," Journal of Petroleum Exploration and Production Technology, vol. 8, no. 3, pp. 743-751, 2018.

[59] D. Petković, Ž. Ćojbašić, V. Nikolić et al., "Adaptive neurofuzzy maximal power extraction of wind turbine with continuously variable transmission," Energy, vol. 64, pp. 868-874, 2014.

[60] C. Zhang, A. Ali, and L. Sun, "Investigation on low-cost friction-based isolation systems for masonry building structures: experimental and numerical studies," Engineering Structures, vol. 243, Article ID 112645, 2021.

[61] R. M. Nejad, F. Berto, G. Wheatley, M. Tohidi, and W. Ma, "On fatigue life prediction of Al-alloy 2024 plates in riveted joints," Structures, vol. 33, pp. 1715-1720, 2021.

[62] C. C. Chung, L. C. Chao, and S. J. Lou, "The establishment of a green supplier selection and guidance mechanism with the ANP and IPA," Sustainability, vol. 8, no. 3, p. 259, 2016.

[63] R. K. Mavi, "Green supplier selection: a fuzzy AHP and fuzzy ARAS approach," International Journal of Services and Operations Management, vol. 22, no. 2, pp. 165-188, 2015.

[64] J. Zhao, J. Liu, J. Jiang, and F. Gao, "Efficient deployment with geometric analysis for mmwave UAV communications," IEEE Wireless Communications Letters, vol. 9, no. 7, pp. 1115-1119, 2020.

[65] Q. Jiang, F. Shao, W. Lin, K. Gu, G. Jiang, and H. Sun, "Optimizing multistage discriminative dictionaries for blind image quality assessment," IEEE Transactions on Multimedia, vol. 20, no. 8, pp. 2035-2048, 2017.
[66] M. Yazdani, P. Chatterjee, D. Pamucar, and M. D. Abad, “A risk-based integrated decision-making model for green supplier selection: a case study of a construction company in Spain," Kybernetes, vol. 49, no. 4, 2019.

[67] I. Dobos and G. Vörösmarty, "Green supplier selection and evaluation using DEA-type composite indicators," International Journal of Production Economics, vol. 157, pp. 273-278, 2014.

[68] H. Jafari, M. Nazari, and S. Shamshirband, "Optimization of energy consumption in wireless sensor networks using density-based clustering algorithm," International Journal of Computers and Applications, vol. 43, no. 1, pp. 1-10, 2021.

[69] M. S. Nikabadi and S. B. Razavian, "A hesitant fuzzy model for ranking maintenance strategies in small and mediumsized enterprises," International Journal of Productivity and Quality Management, vol. 29, no. 4, pp. 558-592, 2020.

[70] M. Rezaei and N. Naderi, "Persian signature verification using fully convolutional networks,” 2019, https://arxiv.org/ abs/1909.09720.

[71] H. M. W Chen, S. Y. Chou, Q. D. Luu, and T. H. K. Yu, “A fuzzy MCDM approach for green supplier selection from the economic and environmental aspects," Mathematical Problems in Engineering, vol. 2016, Article ID 8097386, 10 pages, 2016.

[72] J. Liu, Y. Liu, and X. Wang, "An environmental assessment model of construction and demolition waste based on system dynamics: a case study in Guangzhou," Environmental Science and Pollution Research, vol. 27, no. 30, pp. 37237-37259, 2020.

[73] S. Xu, J. Wang, W. Shou, T. Ngo, A. M. Sadick, and X. Wang, "Computer vision techniques in construction: a critical review," Archives of Computational Methods in Engineering, vol. 28, no. 2, pp. 1-15, 2020.

[74] R. Liang and H. Y. Chong, "A hybrid group decision model for green supplier selection: a case study of megaprojects," Engineering Construction and Architectural Management, vol. 26, no. 8, 2019.

[75] W. Song, Z. Chen, A. Liu et al., "A study on green supplier selection in dynamic environment," Sustainability, vol. 10, no. 4, p. 1226, 2018.

[76] J. Liu, Y. Yi, and X. Wang, "Exploring factors influencing construction waste reduction: a structural equation modeling approach," Journal of Cleaner Production, vol. 276, Article ID 123185, 2020.

[77] A. Davarpanah, "Parametric study of polymer-nanoparticles-assisted injectivity performance for axisymmetric two-phase flow in EOR processes," Nanomaterials, vol. 10, no. 9, p. 1818, 2020.

[78] F. Bahramian, A. Akbari, M. Nabavi, S. Esfandi, E. Naeiji, and A. Issakhov, "Design and tri-objective optimization of an energy plant integrated with near-zero energy building including energy storage: an application of dynamic simulation," Sustainable Energy Technologies and Assessments, vol. 47, no. 1, Article ID 101419, 2021.

[79] A. Davarpanah, R. Shirmohammadi, B. Mirshekari, and A. Aslani, "Analysis of hydraulic fracturing techniques: hybrid fuzzy approaches," Arabian Journal of Geosciences, vol. 12, no. 13, pp. 1-8, 2019.

[80] L. Demir, M. E. Akpınar, C. Araz, and M. A. Ilgın, "A green supplier evaluation system based on a new multicriteria sorting method: VIKORSORT," Expert Systems with Applications, vol. 114, pp. 479-487, 2018.

[81] Z. Xu, J. Qin, J. Liu, and L. Martinez, "Sustainable supplier selection based on AHPSort II in interval type-2 fuzzy environment," Information Sciences, vol. 483, pp. 273-293, 2019. 
[82] H. Karimmaslak, B. Najafi, S. S. Band, S. Ardabili, F. Haghighat-Shoar, and A. Mosavi, "Optimization of performance and emission of compression ignition engine fueled with propylene glycol and biodiesel-diesel blends using artificial intelligence method of ANN-GA-RSM," Engineering Applications of Computational Fluid Mechanics, vol. 15, no. 1, pp. 413-425, 2021.

[83] M. Yazdani, Z. Wen, H. Liao, A. Banaitis, and Z. Turskis, "A grey combined compromise solution (CoCoSo-G) method for supplier selection in construction management," Journal of Civil Engineering and Management, vol. 25, no. 8, pp. 858-874, 2019.

[84] A. Chapnevis, İ. Güvenç, L. Njilla, and E. Bulut, "Collaborative trajectory optimization for outage-aware cellular-enabled UAVs," in Proceedings of the 2021 IEEE 93rd Vehicular Technology Conference (VTC2021-Spring), pp. 1-6, IEEE, Helsinki, Finland, April 2021.

[85] H. W. Lo, J. J. Liou, H. S. Wang, and Y. S. Tsai, “An integrated model for solving problems in green supplier selection and order allocation," Journal of Cleaner Production, vol. 190, pp. 339-352, 2018.

[86] Q. Wu, L. Zhou, Y. Chen, and H. Chen, "An integrated approach to green supplier selection based on the interval type-2 fuzzy best-worst and extended VIKOR methods," Information Sciences, vol. 502, pp. 394-417, 2019.

[87] B. Bathaei, The Architectural System of Persian Enclosed Garden: Recognition \& Recreating of the Concept of Persian Garden, LAP LAMBERT Academic Publishing, Sunnyvale, CA, USA, 2020.

[88] M. Igarashi, L. de Boer, and A. M. Fet, "What is required for greener supplier selection? a literature review and conceptual model development," Journal of Purchasing and Supply Management, vol. 19, no. 4, pp. 247-263, 2013.

[89] M. K. Buniya, I. Othman, R. Y. Sunindijo, A. F. Kineber, E. Mussi, and H. Ahmad, "Barriers to safety program implementation in the construction industry," Ain Shams Engineering Journal, vol. 12, no. 1, pp. 65-72, 2021.

[90] D. D. Camacho, P. Clayton, W. J. O’Brien et al., “Applications of additive manufacturing in the construction industry-a forward-looking review," Automation in Construction, vol. 89, pp. 110-119, 2018.

[91] B. Bathaei, "Persian enclosed garden: recognition \& recreation of the Persian garden," Revista Şcolii Doctorale de Urbanism, vol. 1, no. 1, pp. 53-56, 2016.

[92] B. Bathaei, Process Analysis of Environmental Perception of Persian Garden Based on Psychological Theory of Environment, Editura Universitar "Ion Mincu", Bucharest, Romania, 2016.

[93] B. Bathaei, "Change is of the essence, regenerating of brown fields (landscape revitalization of Tehran's brick kilns)," in Proceedings of the 2nd International Conference on Architecture, Structure and Civil Engineering (ICASCE'16), London, UK, March 2016.

[94] B. Bathaei, "Achieving sustainable city by the concept of Persian garden," Acta Technica Napocensis: Civil Engineering \& Architecture, vol. 61, no. 3, 2018.

[95] S. H. Mafuku, "Greening the construction industry in Zimbabwe," The Sustainability Ethic in the Management of the Physical, Infrastructural and Natural Resources of Zimbabwe, p. 361, Langaa RPCIG, Bamenda, Cameroon, 2019.

[96] S. A. S. Haeri and J. Rezaei, "A grey-based green supplier selection model for uncertain environments," Journal of Cleaner Production, vol. 221, pp. 768-784, 2019.
[97] L. Gigović, D. Pamučar, Z. Bajić, and M. Milićević, "The combination of expert judgment and GIS-MAIRCA analysis for the selection of sites for ammunition depots," Sustainability, vol. 8, no. 4, p. 372, 2016.

[98] M. A. Medvedeva, T. E. Simos, and C. Tsitouras, "Exponential integrators for linear inhomogeneous problems," Mathematical Methods in the Applied Sciences, vol. 44, no. 1, pp. 937-944, 2021.

[99] M. A. Medvedeva, T. E. Simos, and C. Tsitouras, "Sixthorder, P-stable, Numerov-type methods for use at moderate accuracies," Mathematical Methods in the Applied Sciences, vol. 44, no. 8, pp. 6923-6930, 2021.

[100] T. E. Simos and C. Tsitouras, "Explicit, ninth order, two step methods for solving inhomogeneous linear problems $x^{\prime \prime}(t)=$ $\Lambda x(t)+f(t), "$ Applied Numerical Mathematics, vol. 153, pp. 344-351, 2020.

[101] M. A. Medvedeva, T. E. Simos, and C. Tsitouras, "Variable step-size implementation of sixth-order Numerov-type methods," Mathematical Methods in the Applied Sciences, vol. 43, no. 3, pp. 1204-1215, 2020.

[102] G. Graham, J. Freeman, and T. Chen, "Green supplier selection using an AHP-entropy-TOPSIS framework," Supply Chain Management, vol. 20, no. 3, pp. 327-340, 2015.

[103] J. Qin, X. Liu, and W. Pedrycz, "An extended TODIM multicriteria group decision making method for green supplier selection in interval type-2 fuzzy environment," European Journal of Operational Research, vol. 258, no. 2, pp. 626-638, 2017.

[104] K. Q. Wang, H. C. Liu, L. Liu, and J. Huang, "Green supplier evaluation and selection using cloud model theory and the qualiflex method," Sustainability, vol. 9, no. 5, p. 688, 2017.

[105] A. E. Cengiz, O. Aytekin, I. Ozdemir, H. Kusan, and A. Cabuk, "A multicriteria decision model for construction material supplier selection,” Procedia Engineering, vol. 196, pp. 294-301, 2017.

[106] O. Babalola, E. O. Ibem, and I. C. Ezema, "Implementation of lean practices in the construction industry: a systematic review," Building and Environment, vol. 148, pp. 34-43, 2019.

[107] M. Ahmed, M. J. Thaheem, and A. Maqsoom, "Barriers and opportunities to greening the construction supply chain management," Benchmarking: An International Journal, vol. 27, no. 3, 2019.

[108] A. Oke, D. Aghimien, C. Aigbavboa, and C. Musenga, "Drivers of sustainable construction practices in the Zambian construction industry," Energy Procedia, vol. 158, pp. 3246-3252, 2019.

[109] A. A. Lekvan, R. Habibifar, M. Moradi, M. Khoshjahan, S. Nojavan, and K. Jermsittiparsert, "Robust optimization of renewable-based multi-energy micro-grid integrated with flexible energy conversion and storage devices," Sustainable Cities and Society, vol. 64, Article ID 102532, 2021.

[110] A. Davarpanah and B. Mirshekari, "A mathematical model to evaluate the polymer flooding performances," Energy Reports, vol. 5, pp. 1651-1657, 2019.

[111] M. Xia and Z. Xu, "Hesitant fuzzy information aggregation in decision making," International Journal of Approximate Reasoning, vol. 52, no. 3, pp. 395-407, 2011.

[112] R. M. Rodriguez, L. Martinez, and F. Herrera, "Hesitant fuzzy linguistic term sets for decision making," IEEE Transactions on Fuzzy Systems, vol. 20, no. 1, pp. 109-119, 2011.

[113] I. Badi and M. Ballem, "Supplier selection using the rough BWM-MAIRCA model: a case study in pharmaceutical supplying in Libya," Decision Making: Applications in Management and Engineering, vol. 1, no. 2, pp. 16-33, 2018. 